\title{
Preparation of Perfluorinated Surfactant Activates for Antifouling Paints
}

\author{
A. Bacha ${ }^{1}$, R. Méghabar ${ }^{2}$ \\ ${ }^{1}$ Chemistry Laboratory, Faculty of Sciences and Technology, University of Djelfa, Djelfa, Algeria; ${ }^{2}$ Laboratory of Polymer Chemis- \\ try, University of Es-Senia, Oran, Algeria. \\ Email:mbamalo@yahoo.com
}

Received July $8^{\text {th }}, 2012$; revised August $15^{\text {th }}, 2012$; accepted August $26^{\text {th }}, 2012$

\begin{abstract}
Antifouling paints are the most reliable way to prevent biofouling of submerged surfaces. The high toxicity of organotin paints, prompted us to look for ideas to develop paints that do not present environmental risks. In this work, we prepare a painting by a modification of acrylic acid monomer containing a free carboxyl group. The biocide that is selected is the perfluorinated chain with eight carbons. Chemical modifications of the resins are made through a radical reaction. The magnitudes of changes are monitored by proton nuclear magnetic resonance NMR, gel permeation chromatography (GPC) and the light scattering (LS) at a fixed angle $90^{\circ}$. The glass transition temperature of the surfactant is obtained by the differential scanning calorimetry (DSC). The antifouling properties of the paint are followed by exposure of panels to the marine environment by visual observation.
\end{abstract}

Keywords: Surfactant; Antifouling; Glass Transition Temperature; Aluminum Panels; Differential Scanning Calorimetry; Critical Micelle Concentration (CMC)

\section{Introduction}

The paintings with fluorine atoms are used in many applications and this is due to their unique properties like low surface tension, non-adhesive nature and antifouling properties along. Fluorine is difficult to polarize. This is especially advantageous for their applications in surface coatings. Hence fluoropolymers can hinder water reaching the metallic surface in tow ways: fluorinated polymers are not wetted by water and secondly the molecular absorption of water into these polymers is relatively small [1]. During recent years, the most successful antifouling marine paints are those consisting of triorganotin-based. They are hydrolysable polymers containing triorganotin ester groups that are released by a reaction with seawater. However, the high toxicity of these compound has been shown [2-4]. These environmental concerns lead to develop new antifouling paints, environmental friendly and effective over the long term. Our work concerns the synthesis of products (perfluorinated surfactants) that can enter into the formulation of antifouling paints by an economic way.

Perfluorinated surfactants are classified as biocides [5]. In particular salts with perfluorinated chain with at least eight carbons are effective biocides [6]. The most common way to present these compound is the radical telomerization [7]. The synthesis involves a single step
(Figure 1).

The product is a surfactant with a hydrophobic carbon chain and a hydrophilic portion represented by a function in the same loaded organic molecule [8-9]. This property provides a potentially effective antibacterial effect [9]. This article describes the synthesis, characterization and biocidal potential of this new surfactant molecule.

\section{Experimentation}

\subsection{Materials}

The perfluorinated acrylic surfactant (PAS) was synthesized in the physics laboratory materials, Faculty of Science and Technology (University of Djelfa (Algeria)), this synthesis is described in detail in Section 2.3.

The product used is compared with tributyltin (TBT) nonfluorinated synthesized in the laboratory of polymer chemistry at the University of Oran Es-Senia (Algeria) [10]. The product was vacuum distilled before use and stored at $0^{\circ} \mathrm{C}$ to avoid thermal polymerization. Azoisobutyronitrile (AIBN) and perfluorinated thiol were used

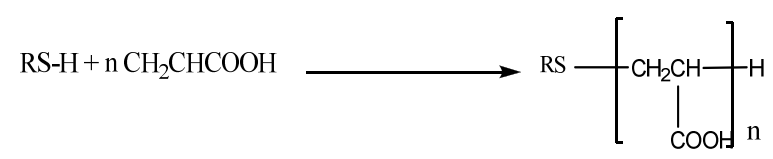

Figure 1. Telomerization of acrylic acid $\left(R \equiv \mathrm{C}_{8} \mathrm{~F}_{17} \mathrm{C}_{2} \mathrm{H}_{4^{-}}\right)$ 
as a free radical initiator and a chain transfer agent, respectively. The solvents like tetrahydofuran (THF), acetonitrile, pentane, diethyl ether (Merck) and analytical products were used directly without further purification. Water was deionized.

\subsection{Measures}

Proton NMR measurements were performed on a Brucker WB 360 spectrometer (ref. Internal $\mathrm{CDCl}_{3}$ ). Chemical shifts are expressed in $10^{-6}$.

The determination of critical micelle concentrations of PSA product is given by the light scattering (LS) at a fixed angle $90^{\circ}$. The optical constant of the device (under the experimental conditions used here) is $\mathrm{K}=0735.10^{2}$.

The relative molecular weight and molecular weight distributions were determined by the gel permeation chromatography (GPC), the device with THF as eluent, flow rate: $0.8 \mathrm{ml} / \mathrm{min}$, volume of injection loop: $0.2 \mathrm{ml}$, with two columns as support a mixed gel porosity and particle size of $10 \mu$ and differential refractometer (BricePhoenix) as concentration detector $(\lambda=632 \mathrm{~nm})$.

Thermogram of Differential Scanning Calorimetry (DSC) was taken on an appliance model Mettler TA 4000 at a heating rate of $10^{\circ} \mathrm{C} / \mathrm{min}$. Temperature $(T g)$ was taken at the beginning of the jump corresponding to the heat capacity

\subsection{Telomerization of Acrylic Acid}

A mixture of $7.2 \mathrm{~g}(0.1 \mathrm{~mol})$ of acrylic acid, $36 \mathrm{~g}(0.075$ mol) of perfluorinated thiol is added dropwise to $0.164 \mathrm{~g}$ $\left(10^{-3} \mathrm{~mol}\right)$ of AIBN in $100 \mathrm{ml}$ of THF. The mixture was left stirring under nitrogen bubbling at THF reflux for four hours at $80^{\circ} \mathrm{C}$. After concentration, the reaction mixture was precipitated in acetonitrile to remove the thiol and the remaining monomer. The product obtained was dried under vacuum. ${ }^{1} \mathrm{H}$ NMR $\left(\mathrm{D}_{2} \mathrm{O}\right): \delta(\mathrm{ppm}): 2.6$; 2.75 (m, 4H, $\mathrm{CH}_{2} \mathrm{SCH}_{2}$ ); 2.8; 2.9 (t, 2H, $\left.\mathrm{CH}_{2} \mathrm{COO}\right) ; 3.3$; $3.4\left(\mathrm{~s}, \mathrm{C}_{8} \mathrm{~F}_{17} \mathrm{CH}_{2}\right)$.

\subsection{Determination of Critical Micelle Concentration}

Fundamental solutions are obtained by dissolving the product in $50 \mathrm{ml}$ of distilled THF solvant. The solutions were then diluted volumetrically generally reports $3 / 4$, $1 / 2$ and $1 / 4$, different solutions were clarified by centrifugation at $18000 \mathrm{rev} / \mathrm{min}$ for 4 hours.

The concentration range studied, respectively: $0.36 \times$ $10^{-4}$ and $2.04 \times 10^{-4} \mathrm{~g} / \mathrm{ml}$.

\subsection{Preparation of Painting and the Panels}

The panels used are of rectangular shapes $(7.5 \mathrm{~cm} \times 6.5$ $\mathrm{cm})$ aluminum, $3 \mathrm{~mm}$ thick; test paints were applied directly using a flat brush on the surface of the panel with the previously scraped sandpaper, cleaned and washed with methanol. Each panel is painted on both sides by double layers, leaving at least 24 hours between the two applications.

After a drying time (up to one week), the panels are arranged and fixed on a metal support. The painted panels are called as a witness P1, P2 perfluorinated acrylic surfactant (PAS), and P3 (TBT).

The painting of the PSA is prepared by dissolving the resin (35 parts) in methoxy-propanol-2 (65 parts). The formulations are prepared in a laboratory dissolver.

\subsection{Exposure to the Marine Environment}

All panels are put to tests to evaluate its biocidal properties. For this, the panels were painted immersed to a depth of $4 \mathrm{~m}$ in the port of Oran, near the wharf customs dock in the sports complex (Rowing), during twenty-four months corresponding to four cold and warm seasons.

Oran is the second economic city located west of Algeria. The salinity and temperature of the location are in Table 1.

Panels are photographed and study of the behavior of marine fouling deposit is made (the date of immersion is March 2009).

Photos were taken by a camera Samsung Lens $3 \mathrm{X}$ zoom 6.2 - $18.6 \mathrm{~mm} \mathrm{2.8} \mathrm{-} \mathrm{5.2.} \mathrm{10.2} \mathrm{Mega} \mathrm{Pixels} \mathrm{Intelli-}$ gent LCD.

\section{Results and Discuss}

\subsection{Synthesis of Perfluorinated Acrylic Surfactant (PAS)}

The preparation of acrylic polymers of low molecular mass [11] is of major importance. The products obtained are soluble in water and found many applications.

The presence of fluorescent atoms along the chain determines the degree of polymerization of the surfactant.

\subsection{Gel Permeation Chromatography of PAS}

The curve of Figure 2 shows the evolution of the signal intensity as a function of elution volume of surfactant (PAS).

It is observed that the maximum intensity of the peak in the chromatogram appears to $36.06 \mathrm{ml}$, the peak is narrow and symmetric product of typical well-defined

Table 1. Changes in physicochemical parameters of the natural sea water at the port of Oran in 2010.

\begin{tabular}{cccc}
\hline Temperature & $\mathrm{pH}$ & $\begin{array}{c}\text { Salinity } \\
(\%)\end{array}$ & $\begin{array}{c}\text { Conductivity } \\
(\mathrm{mS} / \mathrm{cm})\end{array}$ \\
\hline $10-23$ & $8.4-8.8$ & $34-36$ & $39-45$ \\
\hline
\end{tabular}




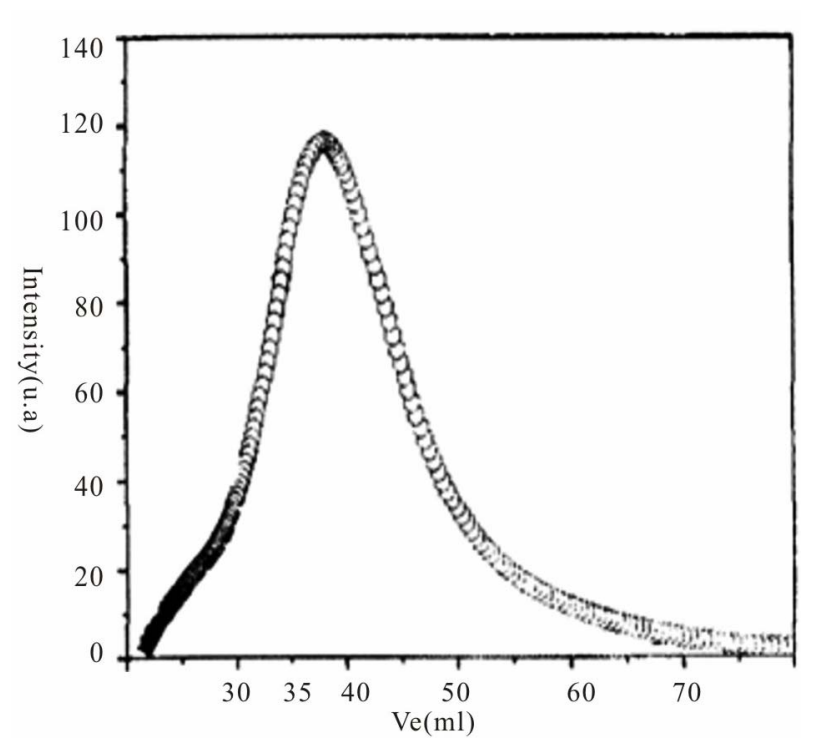

Figure 2. Gel permeation chromatography of perfluorinated acrylic surfactant (PAS).

and iso-molecular. The polydispersity $M_{w} / M_{n}$ was 1.24 , see the Table 2, this chromatogram confirms the homogeneity of the product (Figure 2).

\subsection{Critical Micelle Concentrations (CMC)}

The value of the critical micelle concentration (CMC) of perfluorinated acrylic surfactant (PAS) in the solutions was examined by the technique of light scattering (LS).

The light scattering is sensitive to dust, for this reason we work in harsh conditions.

The general equation for the scattering of light in the case of small molecules (or micelles of small size: less than $12 \mathrm{~nm})$ can be written $[12,13]$ :

$$
\frac{K^{\prime}\left(\frac{\mathrm{d} n}{\mathrm{~d} c}\right)^{2} \cdot c}{\Delta I}=\frac{1}{M}+2 A_{2}
$$

Or $K^{\prime}$ is the optical constant of the device (in the experimental conditions used here, we have $K^{\prime}=0.735$ $\times 10^{2}$ ).

The intensity difference $\Delta \mathrm{I}$ between the solution concentration (c) and the solvent.

The

$$
\frac{\mathrm{d} n}{\mathrm{~d} c}
$$

of the surfactant is -0.0519 . The negative value which is obtained for this product is due to the presence of fluorine atoms.

Fluorine significantly lowers the refractive index of molecules, $A_{2}$ the second virial coefficient related to thermodynamic properties ( $A_{2}$ actually represents the effect of concentration on the scattered intensity) [13].
Table 2. Characterization of perfluorinated acrylic surfacetant (PAS)

\begin{tabular}{cccc}
\hline Surfactant & $\mathrm{V}_{\mathrm{el}}(\mathrm{ml})$ & $\mathrm{M}_{\mathrm{n}}$ & $\mathrm{M}_{\mathrm{w}} / \mathrm{M}_{\mathrm{n}}$ \\
\hline Surfactant PAS & 36.60 & 3800 & 1.24 \\
\hline
\end{tabular}

The results obtained (in a concentration range between $0.36 \times 10^{-4}$ and $2.04 \times 10^{-4} \mathrm{~g} / \mathrm{ml}$ ) are shown in Tables 3(a) and (b) and illustrated in Figure 3 which shows the variations of the scattered intensity as a function of concentration.

These results allow us to located the critical micelle concentration $(\mathrm{CMC})$ around to $1.545 \times 10^{-4} \mathrm{~g} / \mathrm{ml}$. Below this concentration, the slope of curve is relatively large, is explained by the fact that there is not yet micelle formation and because of the translational mobility, the charges from molecules completely dissociated, are free to move. Above the $\mathrm{CMC}$, the slope is smaller than the first and indicates the formation of micelles. Indeed, they have distributed loads (ionized heads) on the micellar surface, and are neutralized by counterions found in the solution. All these factors contribute to the stability of the micelle, which results in a decrease in the mobility of monomers charged.

\subsection{Glass Transition Temperature}

The glass transition temperature was determined by DSC. This method was used in the research laboratory of the Thermophysics in Dunkerque (France). And once validated, this type of analysis could be used for substrates already applied paint finishes. The results obtained by this method are presented in Figure 4.

As a result, one must conclude that there is a critical number of carbon atoms (carbon atoms bond to fluorescence atoms) where the growing reach does not affect the value of the temperature. This could be parsed by the fact that there is no steric effect or significant obstacle in the acrylic matrix between carbons, while that given by the well-TBT alters the thermal properties of the resin [14]. Many studies have been made by DSC to determine the phase diagrams of mixtures and polymer systems $[15,16]$, the thermal properties were carried out in a temperature range from $0^{\circ} \mathrm{C}$ to $200^{\circ} \mathrm{C}$ (Figure 4).

In this curve, three characteristic temperatures were detected.

The emulsion of perfluorinated acrylic surfactant (PAS) showed some weight loss of $2 \%$, which are due to the solvent. The box in Figure 5 shows a change endothermic around $50^{\circ} \mathrm{C}$, which corresponds to the glass transition temperature $\mathrm{Tg}$, then the product is stable up to $60^{\circ} \mathrm{C}$. Chemical decomposition will start after this temperature 
Table 3. (a) Critical micelle concentration (CMC) of perfluorinated acrylic surfactant (PAS); (b) Measurements of light scattering of perfluorinated acrylic surfactant (PAS), after the CMC.

(a)

\begin{tabular}{cccc}
\hline $\mathrm{c} .10^{-4} \mathrm{~g} / \mathrm{ml}$ & $\mathrm{I}(\mathrm{u}, \mathrm{a})$ & $\triangle \mathrm{I}(\mathrm{u}, \mathrm{a})$ & $(\mathrm{c} / \mathrm{I}) 10^{-4}$ \\
\hline 0 & $\mathrm{I}_{\mathrm{o}}=28.85$ & - & - \\
0.495 & 32.69 & 3.0 & 1.20 \\
0.863 & 35.58 & 5.5 & 1.20 \\
1.182 & 37.50 & 8.0 & 1.18 \\
1.41 & 39.42 & 8.0 & 1.22 \\
C. M. C. $=1.545$ & 40.38 & - & - \\
\hline
\end{tabular}

(b)

\begin{tabular}{cc}
\hline $\mathrm{c} .10^{-4} \mathrm{~g} / \mathrm{ml}$ & $\mathrm{I}(\mathrm{u}, \mathrm{a})$ \\
\hline 1.772 & 46.16 \\
2.04 & 52.88 \\
\hline
\end{tabular}

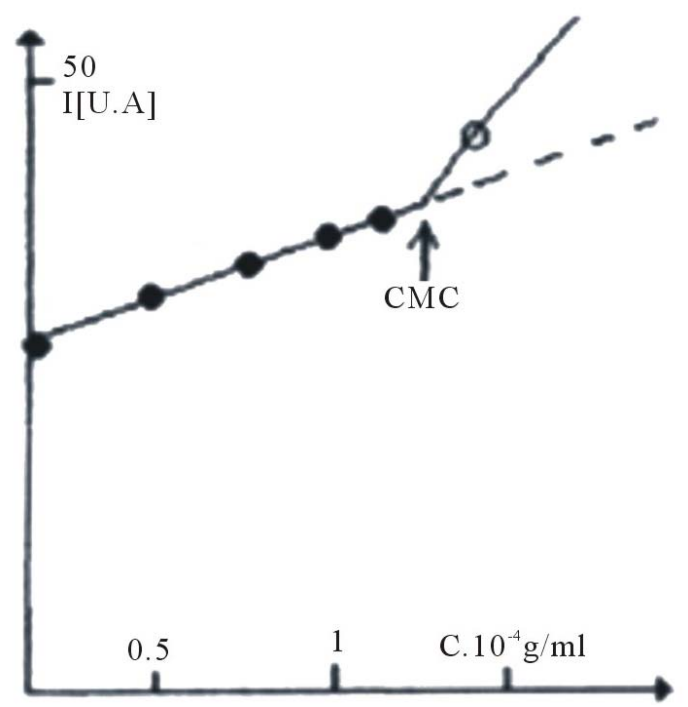

Figure 3. Light scattering of perfluorinated acrylic surfactant (PAS).

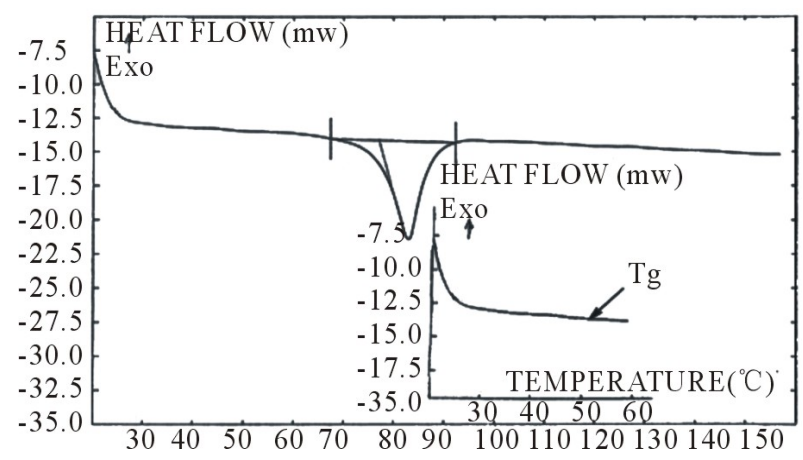

Figure 4. The DSC curve and the value of the glass transition temperature of perfluorinated acrylic surfactant (PAS).

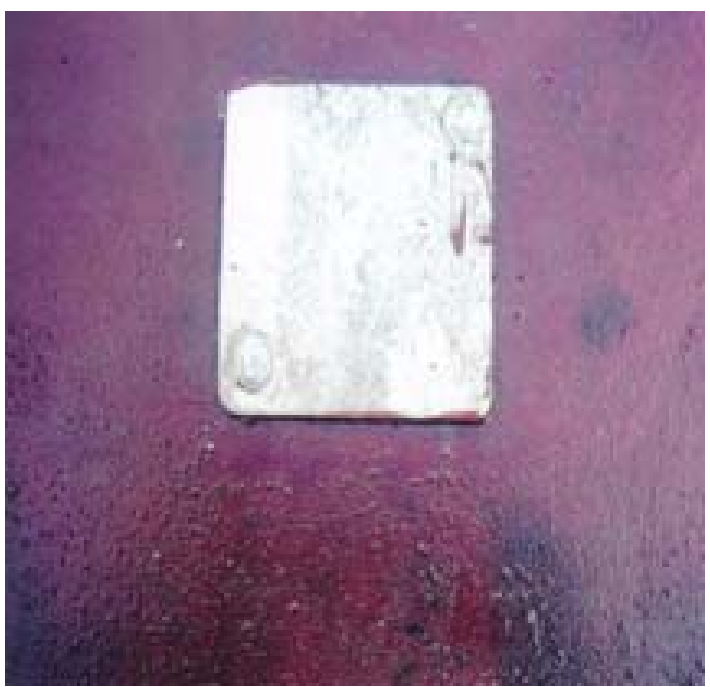

P1

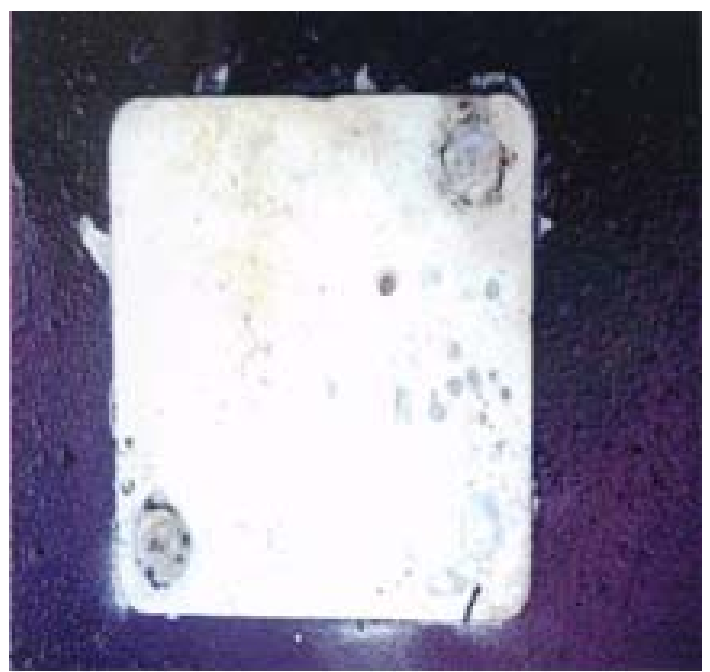

P2

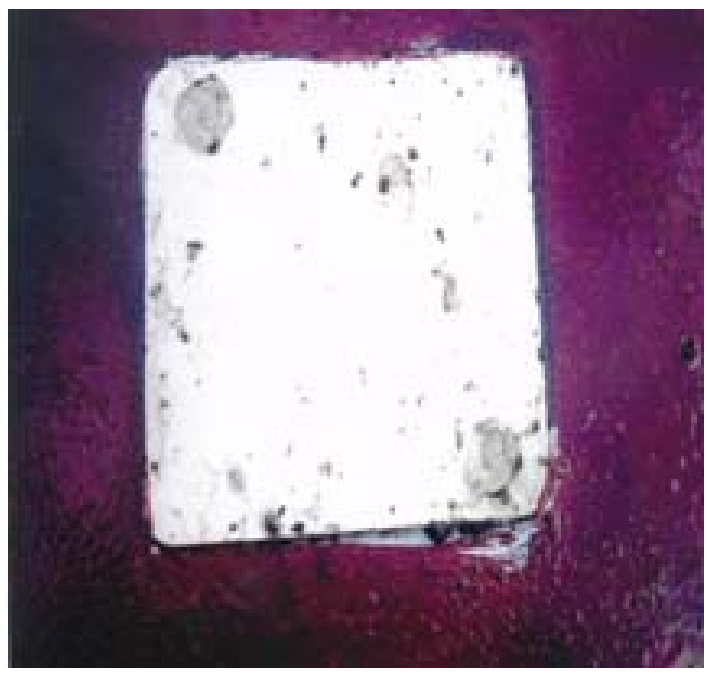

P3

Figure 5. After seven months of immersion, p1 control panel, p2 PAS and p3 TBT. 
and maximum decomposition is around $84^{\circ} \mathrm{C}$ represented in the Figure 4 by a strong endothermic peak $(T m)$.

From these data, it is interesting to note that the surfactant is thermoplastic and its temperature $T m$ remains unchanged even after a second heating.

Experiments are limited to a temperature of $200^{\circ} \mathrm{C}$ to avoid the evaporation of the product.

\subsection{Application to the Marine Environment}

Perfluorinated surfactants are very effective agents, antifouling properties are monitored for exposure to the marine environment, the images corresponding to the seventh month (September 2009) of immersion are presented in Figure 5.

There no attack and no fixing of fouling. All panels have excellent protection against the development of organisms, except a slight difference in the panel P2, which corresponds to the acrylic resin there was spots on its surface.

On the other hand, there are several inhomogeneous spots on the panel P3 (TBT). The witness panel P1 is just slightly swollen, no real attack.

After twelve months (Figure 6), the panel P1 is attacked by marine organisms, a green layer appeared all along the surface; there is a higher swelling of the left side of the panel P3 (TBT). This phenomenon seems to be the first part of the erosion, which propagates the inside of the panel.

These results were confirmed after twenty months of immersion (see Figure 7). For the panel P2, the paint is still present. However this behavior seems to be mainly controlled by hydrophobic-hydrophilic balance of the surfactant.

In this period, first we announce that the witness panel $\mathrm{P} 1$, is completely covered by fouling, as green algae and barnacles. These organizations are well attached marine. On the contrary, the panels P2 and P3 have a swelling in the surrounding, which propagates progressively towards the inner panel. These paintings show an effective biocide. Note that the rate of swelling of P2 is less than P3 (TBT).

Regarding the development of green algae, and comparing the images $c$ and $b$ of Figure 7, we see that the second (P2), has a potential biocidal important. This result is in good agreement with literature [9].

The panel P2 has a biocidal effect of long-term than the $\mathrm{P} 3$ and more the perfluorinated surfactant has not effect as TBT toxicity [14].

In other words, the nature of the atoms that are external $\left(-\mathrm{CF}_{3}\right)$ is independent of the nature and the arrangement of atoms which are located inside the chain (backbone chain), this gives mechanical stability and surface properties specific to the surfactant (wettability of the surfaces) [17-19].

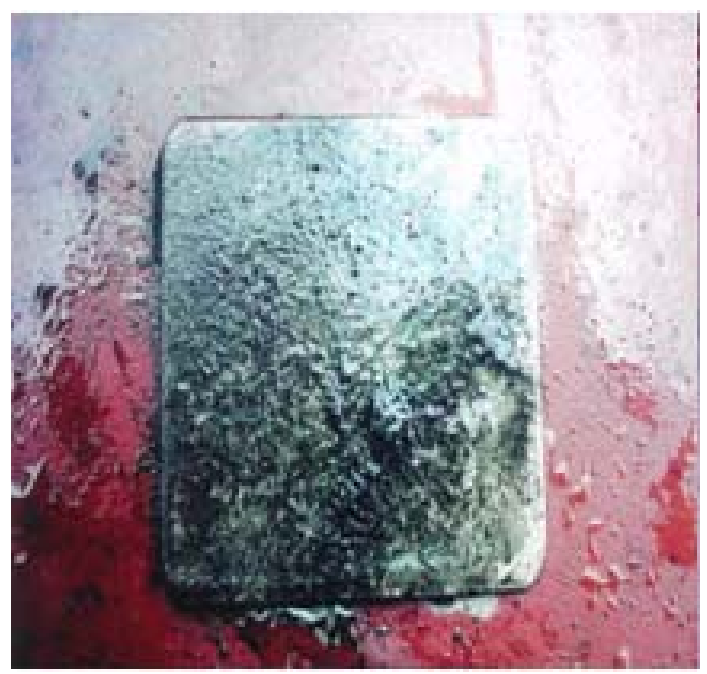

P1

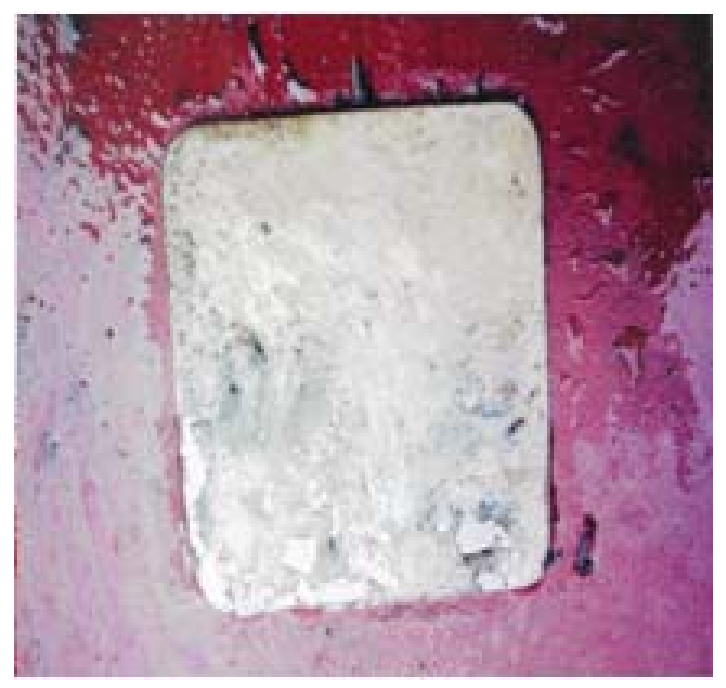

P2

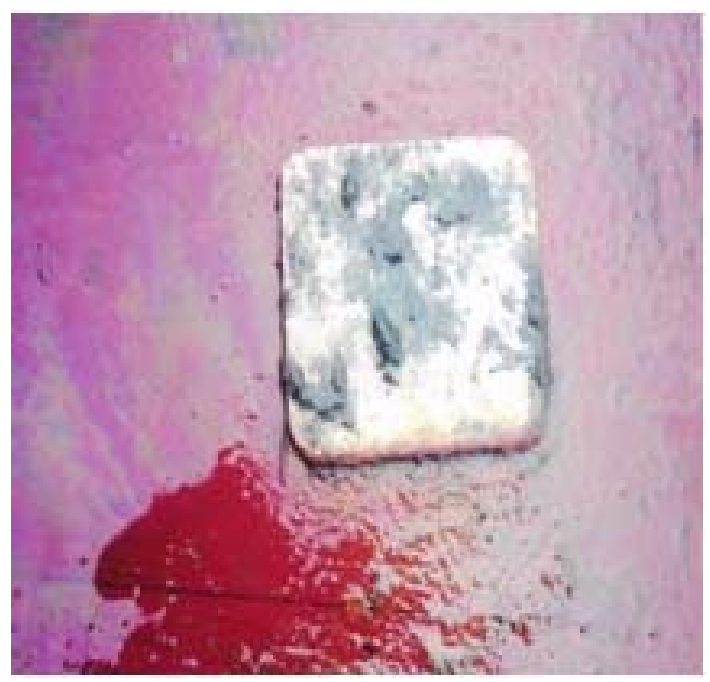

P3

Figure 6. After 12 months P1) control panel, P2) PAS and P3) TBT. 


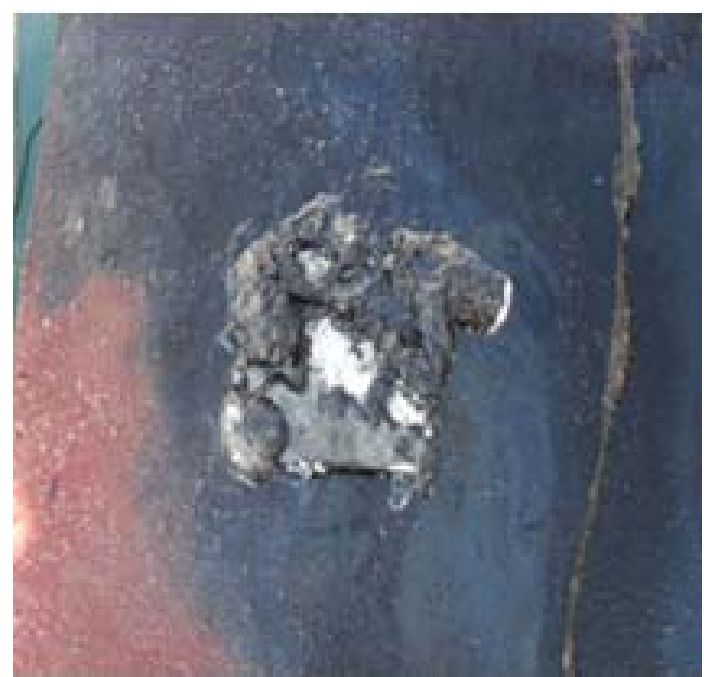

P1

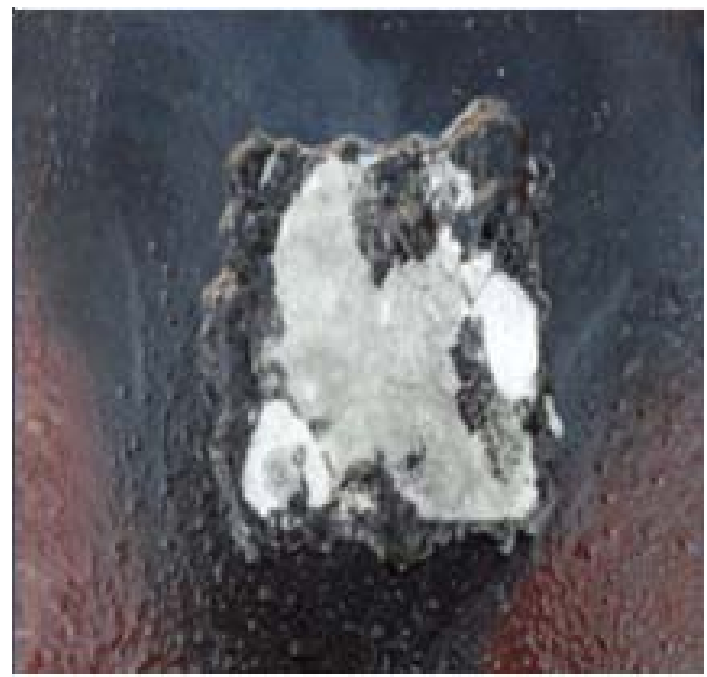

P2

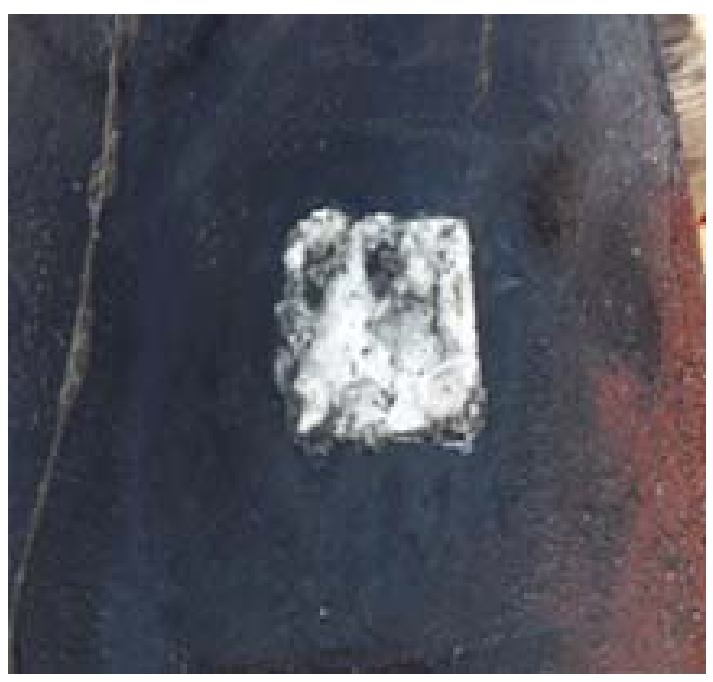

P3

Figure 7. After 20 months P1) control panel, P2) PAS and P3) TBT.
Therefore, the perfluorinated compound (PAS) has a strength that allows him to stay on the surface, it is perpendicular to the matrix $[20,21]$.

\section{Conclusions}

The need to file biocide performance is always larger in the field of paint, this paved the way in recent years, a fruitful research both fundamental and applied. The desired properties are primarily to improve the effectiveness, duration of action, and decreased toxicity and reduced usage price. The solution adopted is to temporarily fix a biocidal agent, chosen for its extensive range of activity based on the protection needed.

Our research efforts have focused primarily on the preparation of biocide molecule (surfactant PAS) and see its behavior as antifouling paint.

The results obtained are:

1) From the study by the gel permeation chromatography (GPC), we can say that the chromatogram led to noticeable results that are qualitatively consistent. In addition, for this surfactant, the mass ratio gave 1.24. Furthermore, the results of the Tables 3(a) and (b), allow us to see that the perfluorinated surfactant PAS present in dilute media (before the $\mathrm{CMC}$ ), a significant degree of association $(\mathrm{Mn}=3800)$, then a critical micelle concentration (CMC) of $1.545 \times 10^{-4} \mathrm{~g} / \mathrm{ml}$, and beyond the CMC, the surfactant PAS has a large mass, we are in the presence of large micelles repellency.

2) The plot of differential scanning calorimetry (DSC) gives excellent results, which makes this method a reliable tool in the study of glass transition temperature of organic coating systems. From these data, it is interesting to note that the acrylic surfactant resulting is thermoplastic and temperatures $T g$ and $T m$ remains unchanged even after a second heating.

3) The processing of panels, gives us the most obvious difference when their protective capacity of corrosion. The perfluorinated product showed better protection than non-fluorinated (TBT). The presence on a fluorine of quantity of $2 \%-10 \%$ showed significantly improved the protective properties.

4) In this study, the amount of agent used PAS (5\% $10 \%$ ) was much less than that used in conventional paints, which is $20 \%-30 \%$ of the total. Thus the mechanical properties of surfactant PAS can be further improved.

These fluorinated products can be used as coat, which may limit moisture from reaching the outside and inside the metal and generally give a longer life to the paintings.

In this study, we used a simple product non-hazardous with fluorine atoms as a main chain. The panels are in the water until now.

\section{Acknowledgements}

The author thanks, Professor Hadj Abdelhafid Sahraoui 
and his team of Thermophysical of the condensed matter-Maison de la Recherche Environnement IndustrielDunkerque (University, Lille III).

\section{REFERENCES}

[1] V. C. Malsh and N. S. Sangaj, "Fluorinated Acrylic Copolymers Part I : Study of Clear Coatings," Progress in Organic Coatings, Vol. 53, No. 3, 2005, pp. 207-211.

[2] S. M. Al-Ghais, S. Ahmad and B. Ali, "Differential Inhibition of Xenobiotic-Metabolizing Carboxylesterases by Organotins in Marine Fish," Ecotoxicology and Environmental Safety, Vol. 46, No. 3, 2000, pp. 258-264.

[3] J. G. Vos, E. Dybing, H. A. Greim, O. Ladefoged, C. Lambre, J. V. Tarazona, I. Brandt and A. D. Vathaak, "Health Effects of Endocrine-Discrupting Chemicals on Wildlife, with Special Reference to the European Situation,"Critical Reviews in Toxicology, Vol. 30, No. 1, 2000, pp. 71-133.

[4] USEPA, "Ambient Aquatic Life Water Quality Criteria for Tributyltin (TBT)," United States Environmental Protection Agency, Washington DC, 2003. http://www.epa.gov

[5] V. C. Malsh and N. S., Sangaj, "Fluorinated Acrylic Copolymers: Part I. Study of Clear Coatings," Progress in Organic Coatings, Vol. 53, No. 3, 2005, pp. 207-211. doi:10.1016/i.porgcoat.2005.03.003

[6] C. Leroy, "Lutte Contre les Salissures Marines: Approche par procéDés Enzymatiques," Ph.D. Thesis, Institut National des Sciences Appliquées, Toulouse, 2006.

[7] B. Gupta, N. Muzyyan, S. Saxena, N. Grover and S. Alam, "Preparationof Ion Exchange Menbranes by Radiation Grafting of Acrylic Acid on FEP Films," Radiation Physics and Chemistry, Vol. 77, No. 1, 2008, pp. 42-48. doi:10.1016/j.radphyschem.2007.03.007

[8] H.-H. Chu, Y.-S. Yeo and K. S. Chuany, "Entry in Emulsion Polymerization Using a Mixture of Sodium Polystyrene Sulfonate and Sodium Dodecyl Sulfate as Surfactant," Polymer, Vol. 48, No. 8, 2007, pp. 2298-2305. doi:10.1016/j.polymer.2007.02.057

[9] R. Jellali, "Elaboration des Revetements Antifouming par Photoréticulation D'oligoisoprènes Fonctionnalisés: Etude de Leur Activités antibactÉriennes, Antifongiques et Antialgales," Ph.D. Thesis, University of Maine, Orono, 2008.

[10] B. Belbachir, "Synthèse et Étude de Macromonomères à Activité Biocide: Formulation de Peintures Antisalissure,"
Mémoire de Magister, University Es-Senia Oran, Oran, 1996.

[11] V. I. Minkin, O. A. Osipov and Y. A. Zhdanov, "Dipole Moments in Organic Chemistry," Journal of Chemical Education, Vol. 49, No. 10, 1970, p. A604.

[12] S. Forster and W. Schimtz, Advanced in Polymer Science, Vol. 120, 1995, pp. 53-128.

[13] A. Bacha, "Tensioactifs perfluorés ionique synthèse et études physicochimiques," Editions Universitaires Européennes, 2011.

[14] M. Thouvenin, J.-J. Peron. C. Charreteur, P. Guerin, J.-Y. Langlois and K. Vallee-Rehel, "A Study of the Biocide Release from Antifouling Paints," Progress in Organic Coatings, Vol. 44, No. 2, 2002, pp. 75-83. doi:10.1016/S0300-9440(01)00246-6

[15] U. Maschke, F. Roussel, J. M. Buisine and X. Coqueret, "Liquid-Crystal Polymer Composite-Materials-A Thermophysical and Electrooptical Study," Journal of Thermal Analysis and Calorimetry, Vol. 51, No. 3, 1998, pp. 737-746.

[16] V. Allouchery, F. Roussel, J. M. Buisine and U. Maschke, "Thermodynamic and Electro-Optic Characteristics of UVCured Monofunctional Acrylate/Nematic Liquid Crystal Mixtures," Molecular Crystals and Liquid Crystals Science and Technology: Section A. Molecular Crystals and Liquid Crystals, Vol. 329, No. 1, 1999, pp. 227-237. doi:10.1080/10587259908025944

[17] A. G. Pittman, "Surface Properties of Fluorocarbon Polymers," In: L.A. Wall (Ed.), (Chapter 13), John Wiley and Sons, Inc., Hoboken, 1972.

[18] J. R. Griffith, J. G. O'Rear and S. A. Reins, "Fluorinated Epoxy Resins," Chemical Technology, Vol. 2, No. 5, 1972, pp. 311-316.

[19] D. Anton, "Surface-Fluorinated Coatings," Advanced Materials, Vol. 10, No. 15, 1998, pp. 1197-1205. doi:10.1002/(SICI)1521-4095(199810)10:15<1197::AIDADMA1197>3.0.CO;2-F

[20] M. Delucchi, S. Turri, A. Barbucci, M. Bassi, S. Novelli and G. Cerisola, "Fluoroether Coatings: Relationship of Electrochemical Impedence Spectroscopy Measurements, Barrier Properties and Polymer Structure," Journal of Polymer Science Part B: Polymer Physics, Vol. 40, No. 1, 2002, pp. 52-64.

[21] V.C. Malshe, N.S. Sangaj, "Fluorinated Acrylic Copolymers Part I: Study of Clear Coatings," Progress in Organic Coatings, Vol. 53, No. 3, 2005, pp. 207-211. doi:10.1016/j.porgcoat.2005.03.003 